\title{
Auditing and Re-auditing Nursing Care for Children Receiving Blood Transfusion
}

\author{
Manar M. Sayed ${ }^{1}$, Eman S. Ahmed ${ }^{2}$, Khaled I. Elsayh ${ }^{3}$ and Faranca A. Ahmed ${ }^{4}$. \\ 1. Nursing Specialist, El-Eman General Hospital, Assiut, Egypt. \\ 2. Professor of Pediatric Nursing, Faculty of Nursing, Assiut University, Egypt. \\ 3. Professor of Pediatrics, Faculty of Medicine, Assiut University, Egypt. \\ 4. Lecturer of Pediatric Nursing, Faculty of Nursing, Assiut University, Egypt.
}

\begin{abstract}
Background: pediatric blood transfusion has many potential risks as infections with transmissible disease carried by the donor and transfusion-related acute lung injury which can be decreased by sufficient nursing interventions. Aim to audit and re-audit nursing care for children receiving blood transfusion. Design: descriptive research design was used. Subjects and Method: Sample: This study included all nurses' and nursing supervisors. Setting: the study was conducted in hematology unit, blood transfusion center, pediatric intensive care unit and emergency unit at Assiut University Children Hospital. Subjects: the study consisted of 70 pediatric nurses $(\mathrm{No}=70)$. Tools: A structured observational check-list was used by the researchers to assess nurses' performance about care of children receiving blood transfusion. Re-auditing was performed after giving guidelines to all study research. Results: the majority of nurses had unsatisfactory level of performance before giving brochure and had satisfactory performance level during re-auditing. Conclusion: Auditing nursing care for children receiving blood transfusion was revealed improved nurses' performance after distribution the designed nursing brochure. Recommendation: application of Job Training programs on regular basis suggested improving and updating nurses' performance related to blood transfusion among children.
\end{abstract}

Keywords: Auditing, Nurses' performance, Children, Blood \& Blood transfusion.

\section{Introduction}

Millions of people worldwide receive much needed and life-saving blood transfusions. In the United Kingdom (UK) alone, around 3.4 million blood components transfused every year. Whilst in general, this is a safe practice, morbidity and mortality can still occur in a small number of cases when the procedure is not followed correctly (Oldham et al., 2009) \& (Hajji et al., 2013).

About 300,000 infants are born each year with thalassemia and sickle-cell disease and need regular blood transfusion. While the prevalence of these disorders of hemoglobin is unknown, there is a high requirement for regular transfusion in affected regions, particularly the Mediterranean region, Asia and North Africa (WHO, 2010).

Up to $50 \%$ of all critically ill children admitted to a pediatric intensive care unit (PICU) will receive one or more Red Blood Cell (RBC) transfusions during their stay, increasing to $75 \%$ for children whose stay exceeds 7 days. Anemia may be due to a single factor such as a nutritional deficiency or its cause may be multifactorial. Anemia results from one or more of the following events: loss of RBCs, reduction in the production of RBCs, increased destruction of RBCs, and shorter life span of RBCs (Istaphanous et al., 2011).

Blood is a crucial product in modern medical practice. Red blood cells (RBC) are utilized to enhance oxygen conveyance to tissues in situations of hemorrhage and anemia. Red blood cell transfusion constitutes one of the pillars of treatment in the administration of anemic patients and is one of only a handful couple of medicines that satisfactorily reestablish tissue oxygenation when oxygen request surpasses supply (Wang \& Klein, 2010).

Immediately following birth, all infants universally experience a decrease in hemoglobin $(\mathrm{Hb})$ that results in varying degrees of anemia. Preterm infants are especially vulnerable to these processes for two reasons. First, the severity of the developmental postnatal decrease in $\mathrm{Hb}$ is most pronounced in the least mature infants, placing them at high risk of developing clinically significant anemia. Second, preterm infants are particularly prone to developing severe cardiorespiratory and infectious illnesses, the diagnosis and management of which requires frequent laboratory assessment, resulting in heavy phlebotomy loss (Widness, 2008).

Blood Transfusions commonly in pediatrics, particularly preterm neonates, those with hematologic malignancies or disorders, and children in pediatric intensive care units. In some high-risk intensive care populations, almost $5 \%$ of the pediatric patients receive at least one transfusion during the length of their stay. Children are quite different from adults during growth and development and present a unique set of needs to be considered in therapeutic practice when determining product type, modification, dose, 
rate of delivery, and potential complications of transfusions (Lavoie, 2011, Slonim et al., 2008).

Red blood cell transfusions consider a common intervention with $90 \%$ of extremely low birth weight infants receiving $\mathrm{RBC}$ transfusions/during their stay in the neonatal unit. RBC transfusion is thought to be beneficial in neonates with acute perinatal blood loss and severe anemia; nonetheless, there is growing concern about its association with significant pathologies such as necrotizing enterocolitis (NEC) and intraventricular hemorrhage (Baer et al., 2011, Mohamed \& Shah, 2012).

Blood transfusion practice is the administration of blood component or plasma-derived product to the patient, relative to the current requirements of national guidelines and laws. Transfusion medicine in hospitals is concerned with ensuring that, at time when transfusion is clinically indicated, the patient receives the correct blood safely (Knowles \& Cohen, 2011).

Similarly to the adult total blood volume, these values are vital in the hospital perfusion care, including hemodynamic and pharmacologic interventions, and transfusion practices. The calculation of transfusion volumes in children is very important in order to prevent the risk of circulatory overload. In the UK, many pediatric unit protocols use a calculation of (weight of the patient in $\mathrm{kg}$ ) $\times$ (difference in hemoglobin [Hb] to be achieved in $\mathrm{g} / \mathrm{dL}) \times$ a transfusion factor, usually either 3 or 4 (hazinski, 2013).

Multicenter study in United States involving 35 pediatric teaching hospitals showed that; approximately $0.95 \%$ of patients had blood transfusion reactions: children older than 2 years were the most vulnerable to this event, and most reactions were mild (Slonim et al., 2008).

Although many of the risks associated with blood transfusions have been recognized ever since the beginning of the use of transfusions, the emergence of HIV transmission brought the safety of the blood supply into the limelight of the public. Although challenges remain, significant advances have been made. In Egypt, having the highest recorded prevalence of $\mathrm{HCV}$ antibodies in the world. Prevalence of HCV was reported to be $13.9 \%$ among healthy populations. Adults have higher HCV prevalence $(15.7 \%)$ than children $(4.0 \%)$ (Lehman \& Wilson, 2009).

Blood components transfusion considered transplantation of foreign cells and expose the patient to multiple hazards, including variety of transfusion reactions, diseases and inflammatory complications. The adverse effects and complications associated with blood transfusion include : acute hemolytic transfusion reaction, blood incompatibility, febrile non hemolytic transfusion reaction, allergic reaction , circulatory overload, transfusion related acute bacteremia reactions due to contaminated blood and delayed complications such as delayed hemolysis, viral infection and iron overload (particularly with regular blood transfusion such as in patient with thalassemia (Scott et al., 2016) \& (New, 2016).

National Relative Review of Blood Transfusion of pediatric red cell transfusions detailed that the greater part of pediatric transfusions on non-neonatal departments were given to hematology/oncology patients. Other frequently transfused patients include those on PICU or undergoing cardiac surgery. A huge extent of children is transfused on general as opposed to master pediatric wards. Transfused children frequently have only a single transfusion during their admission and indications for transfusions ought to be followed precisely to guarantee to ensure that they are not given unnecessarily (New et al., 2016).

Studies reviewing transfusion incidents have reported that human error accounts for the overwhelming proportion of failures at the point of blood administration. Typical errors could ascend because of miscommunication between healthcare staff, poor documentation and poor compliance among healthcare professionals with pre-transfusion checking procedures, which could lead to misidentification of errors. It is important to found ways to train and support the staff involved mainly in many transfusion procedures. (Murphy et al., 2009) \& (Sellu et al., 2012)

Physicians make the decision to prescribe blood and blood products. Knowledge of physicians regarding indications for transfusion and the amount of blood and blood products has an important impact on the optimal use of blood and blood products. Both parents have parental responsibility; as a general principle they have the power to give or withhold consent to medical procedures on their children, including consent for blood transfusion (Adams \& Tolich, 2011).

Improper identification of patient as the main cause of mistransfusion resulting in significant transfusion mortality may indicate similar lack of knowledge. Therefore, for nurses to provide high quality care and function effectively, they must have adequate knowledge that they actually use in practice. Bedside administration of blood is an area which mostly needs improvement. This is because transfused patients continued to receive suboptimal care without nurses questioning the evidence base for practice (Taylor et al., 2010).

Blood product transfusions are a valuable health-care resource. Guidelines for transfusion exist, but variability in their application, particularly in children, remains. The quality of care associated with 
blood product transfusion is threatened by avoidable error in practice, and under and over-utilization (Slonim et al., 2008).

Neonates are among the most transfused patients in the hospital but adherence to transfusion guidelines and adoption of unit-specific guidelines vary significantly. Differences exist in the criteria for transfusion, both within units between providers and across units (Baer et al., 2011).

Recent studies suggest that a significant percentage of pediatric transfusion recipients receive only one transfusion during their admission, raising the possibility that some errors may be avoidable (New et al., 2016).

Growing awareness of avoidable risk, and improved reporting systems, have led to a culture of better safety procedures as well as steps to minimize the use of transfusion. However, transfusion errors continue to occur and some serious adverse reactions continue to be unreported. Alternative approaches to patient management should be used to reduce or eliminate the need for transfusion whenever possible (Murph et al., 2013).

The administration of blood transfusion has five interlocked phases, or stages, four of them related to nursing performances which include preparation before collecting blood units from the storage site, blood bag collection, pre-transfusion activities, and post transfusion activities and monitoring to maintain patients 'safety (Hijji et al., 2012).

Preparation of patient prior to blood bag collection in which nurse must check a written prescribe by physician, should provide sufficient information to patients about indication of blood transfusion, its risks and benefits and advantages. Also patent and intravenous set must be available, pre medication and other intravenous solutions should be complete prior to blood transfusion as prescribed (Bielby et al., 2011).

The blood transfusion procedure is a life-threatening procedure so, the nurse should be aware and understand the reaction process. The strict aseptic technique should be followed by hand washing and wearing gloves during receive the blood unit from blood service provider, when attach the blood to the client, and when disconnect the unit. Nurse should assess of IV catheter and size of vein receiving the blood is very important. Additional vital signs measurement during transfusion, including oxygen saturation, according to clinical area and hospital policy should be observed (Marianne, 2016).

Nurse shouldn't receive the blood unit bag if it has clots, air bubbles, or not enclosed in protective cover and she shouldn't shake the blood bag unit strongly to mix its components, it may lead to destruction of blood cells. In addition to not store blood components in nursing unit or another unmonitored refrigerator. Nurse shouldn't keep blood out of a monitored refrigerator for more than 30 minutes before transfusion is started, never warm blood in an unmonitored water bath, or sink, oven. It may cause contamination from bath water. Nurse shouldn't use microwave to warm the blood, this method may damage the blood cells and harm the patient. Red cells must not be warmed above the set point temperature of the approved device, commonly $41^{\circ} \mathrm{C}$. Nurse shouldn't allow any solution other than $0.9 \%$ normal saline to come in contact with the blood component or administration set (Davis, 2012).

Nurse must flush the IV line with normal saline $0.9 \%$ if transfuse more than one blood unit and she shouldn't add medications, including those intended for IV use, to blood or components. Nurse shouldn't infuse through the same administration set as the blood component, never administer a blood component without the appropriate blood filter, she should change blood tubing and filter According to hospital policy and do not transfuse a single unit of blood for more than 4 hours (Ramos et al., 2008).

\section{Aim of the study}

To audit and re-audit nursing care for children receiving blood transfusion.

\section{Research question:}

What are the practical nursing defects related to blood transfusion at Assiut University Children Hospital?

\section{Research Design}

Descriptive research design was used to carry out this study to fit the nature of the problem under investigation.

\section{Setting}

The study was conducted at hematology unit, blood transfusion center, Pediatric intensive care unit and emergency unit at Assiut university children hospital.

\section{Subjects}

The study subjects were (70) nurses including all nurses and nursing supervisors from the previous settings. Pediatric intensive care unit (39) Emergency unit (15) Blood transfusion center (3) Hematology unit (13) respectively.

Tools

Tools of this study was developed by the researcher after reviewing the literature and consisted of two parts:

Part (1): Personal characteristics of the nurses: This part included personal data such as (nurse's name, age, sex, unit, marital status, residence, qualification, years of experiences and training courses received). 
Part (2): Blood Transfusion Monitoring Sheet:

This part included a structured observational checklist (Wilkinson et al., 2015) to assess nurse's performance related to blood transfusion which includes:

\section{Before transfusion}

Verify that informed consent had been obtained, verify the physician's instructions, noting indication, rate of infusion and any premedication orders, verify blood unit (blood group, RH, unit, time received, expired date and types of blood units), obtain vital signs (body temperature, pulse, blood pressure and respiration), obtain the blood product from the blood bank according to agency policy and warm the blood bag.

\section{During transfusion}

Wash hands, wear gloves, using aseptic technique, hang the blood product container on IV pole, attach the distal end of the administration set to the IV catheter, compress the drip chamber of the administration set and allow it to fill up half way, slowly open the roller clamp closest to the blood product, Using the roller clamp, adjust the drip rate, as prescribed, obtain vital signs in 15 minutes, then again in 30 minutes and then hourly while the transfusion infuses and management of abnormal reaction (fever, back pain, chills, itching, shortness of breath) if occur.

\section{Post Transfusion}

Discard the empty blood container and administration set in the proper receptacle according to agency policy, documentation of the date, time (in/out) of infusion, patient's reaction, administration of medication (pre/post transfusion), patient's vital signs and nursing management.

\section{Methods of data collection}

1. An approval was obtained from the directors of the previous settings to collect the necessary data for this study.

2. A pilot study was carried out before starting the data collection on $10 \%$ of nurses to test feasibility and applicability of tool used and they were excluded from the study sample.

3. Validity of tool was reviewed by five experts from medical and nursing staff and content validity index was 0.8 .

4. Internal consistency of reliability was obtained by calculating test -retest and it was 0.70 .

5. Nurse's consent for participation in the study after explaining the aim of the study and confidentiality of obtained data was taken.

6. Data were gathered through observation by using checklist. The checklist had been developed based on literature review and the current standard.

7. The period of the study covered 12 months from January 2017 to January 2018.
8. Guidelines were explained to all nurses who are directly involved in the blood transfusion process after assessing their performance to help them to overcome their defects and promote their performances and it included:

Indication for receiving blood transfusion, nursing role before a blood transfusion, nursing role during a blood transfusion and nursing role after a blood transfusion.

In addition to the potential side effects and the things all healthcare staff should be aware of when caring for someone who has had a blood transfusion and the risks and complications of a blood transfusion.

Re-auditing through observation of nurses' performance regarding care of child receiving blood transfusion by using observational checklist after one month of giving the guidelines.

\section{Scoring system}

To assess the performance of nurses regarding care of child receiving blood transfusion, scoring system was applied;

Each item done correctly $=2$ degrees

Each incorrect or not done item $=0$ degree

Total score of observation checklist were 68 degrees that divided into:

Pre-blood transfusion steps $=36$ degrees

During blood transfusion steps $=28$ degrees

Post blood transfusion steps $=4$ degrees

Nurses who have lesser than $60 \%$ of total score were considered having poor level and it present among $91.4 \%$ of total nurses.

Scores from $60 \%$ to $70 \%$ were considered having satisfactory performance level and it present among $8 \%$ of total nurses.

Greater than $70 \%$ were considered having good level and none of them get it.

Statistical significance at (p-value below 0.05).

A pilot study

A pilot study was carried out before starting the data collection on $10 \%$ of nurses to test feasibility and applicability of tool used and they were excluded from the study sample.

\section{Ethical considerations}

Consent was taken from every nurse after explaining the nature and purpose of the study. Nurses were being assured that the data of this research will not be reused without second permission and they had the right to refuse to participate and/or withdrawal from the study without any rational any time. The study followed common ethical principles in clinical research and There was no risk for study subjects during application of research. Confidentiality and anonymity were assured during this study.

\section{Analysis of data}

Collected data were revised and coded for computerized data entry using statistical Package for 
the Social Sciences (SPSS) version 19. Data were then verified prior to statistical analysis. Statistical methods were applied including descriptive statistics such as (frequency, percentage, mean and standard deviation). P- values were considered as statistically significant when they were less than 0.05 .

\section{Results}

Results of the present study were illustrated according to the following:

1. Personal data.

2. Nurse's performance related to blood transfusion (pre, during and post procedure).

3. Relationships:

- Relationship between nurse's performance level and their years of experience

○ Relationship between Nurse's performance level and their department

○ Relationship between Nurse's performance level and their qualification

- It was found that; all nurses were females (100\%) and all nurses didn't receive training programs related to blood transfusion.

Table (1): Distribution of personal characteristics of studied nurses.

\begin{tabular}{|c|c|c|}
\hline \multirow{2}{*}{ personal characteristics } & \multicolumn{2}{|l|}{ Group } \\
\hline & No. $(n=70)$ & $\%$ \\
\hline \multicolumn{3}{|l|}{ Age: } \\
\hline 20 to $<35$ & 58 & 82.9 \\
\hline 35 to $<50$ & 12 & 17.1 \\
\hline Mean \pm SD & \multicolumn{2}{|l|}{$27.4 \pm 6.6$} \\
\hline Range & \multicolumn{2}{|l|}{$21-34$} \\
\hline \multicolumn{3}{|l|}{ Years of experience: } \\
\hline$<1$ year & 17 & 24.2 \\
\hline 1 to $<10$ & 30 & 42.9 \\
\hline$>10$ & 23 & 32.9 \\
\hline Mean \pm SD & \multicolumn{2}{|c|}{$7.07 \pm 7.6$} \\
\hline Range & \multicolumn{2}{|c|}{1 month -14.67 years } \\
\hline \multicolumn{3}{|l|}{ Department: } \\
\hline Pediatric intensive care unit & 39 & 55.7 \\
\hline Emergency unit & 15 & 21.4 \\
\hline Blood transfusion center & 3 & 4.3 \\
\hline Hematology unit & 13 & 18.6 \\
\hline \multicolumn{3}{|l|}{ Marital Status: } \\
\hline Single & 22 & 31.4 \\
\hline Married & 44 & 62.9 \\
\hline Divorced & 2 & 2.9 \\
\hline Widowed & 2 & 2.9 \\
\hline \multicolumn{3}{|l|}{ Residence: } \\
\hline Rural & 44 & 62.9 \\
\hline Urban & 26 & 37.1 \\
\hline \multicolumn{3}{|l|}{ Qualifications: } \\
\hline Baccalaureate degree & 24 & 34.3 \\
\hline Secondary school of nursing & 25 & 35.7 \\
\hline Technical institute of nursing & 21 & 30.0 \\
\hline
\end{tabular}




\section{practice level}

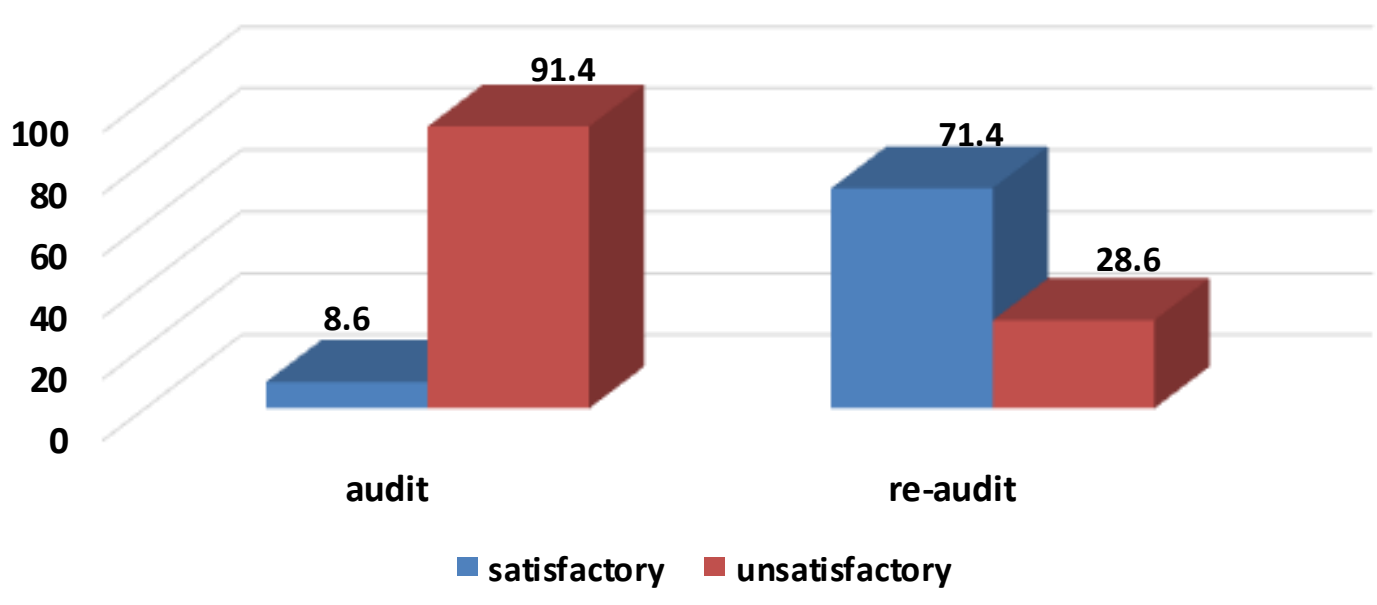

Figure (1): Percentage distribution of nurses according to performance level in the audit and re-audit: Satisfactory $=\geq 60 \%$ of total score Unsatisfactory $=<60 \%$ of total score

Table (2): percentage of nurses with correct performance concerning Pre-blood transfusion Procedure steps during audit and re-audit.

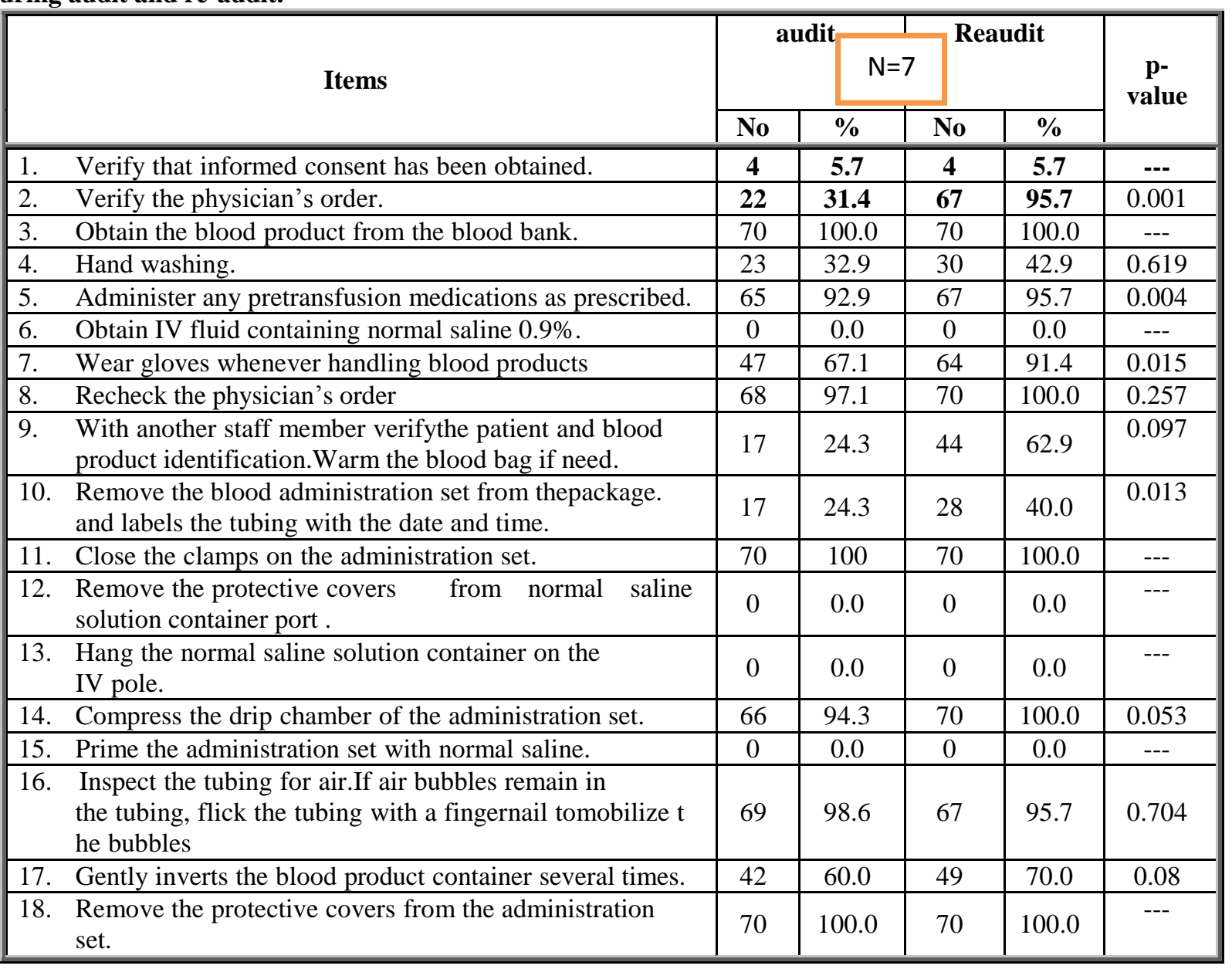


Table (3): percentage of nurses with correct performance during blood transfusion Procedure steps in audit and re-audit.

\begin{tabular}{|c|c|c|c|c|c|}
\hline \multirow[t]{3}{*}{ Items } & \multirow{2}{*}{\multicolumn{2}{|c|}{ audit }} & \multicolumn{2}{|c|}{ Re-audit } & \multirow{3}{*}{$\begin{array}{l}\text { p- } \\
\text { value }\end{array}$} \\
\hline & & & $N=70$ & \multirow[b]{2}{*}{$\%$} & \\
\hline & No. & $\%$ & No. & & \\
\hline 19. Hang the blood product container on the IV pole. & 70 & 100.0 & 70 & 100.0 & --- \\
\hline $\begin{array}{l}\text { 20. Obtain and record the patient's vital signs, including } \\
\text { temperature, before beginning the transfusion. }\end{array}$ & 31 & 44.2 & 51 & 72.9 & 0.019 \\
\hline 21. Wash hands and wear gloves. & 25 & 35.7 & 45 & 64.3 & 0.015 \\
\hline $\begin{array}{l}\text { 22. Using aseptic techniqueattach distal end of administration se } \\
t \text { to the IV catheter. }\end{array}$ & 33 & 47.1 & 39 & 55.7 & 0.025 \\
\hline 23. Compress the drip chamber of the administration set. & 70 & 100.0 & 70 & 100.0 & --- \\
\hline 24. Slowly open the roller clamp. & 69 & 98.6 & 70 & 100.0 & 0.34 \\
\hline 25. Using the roller clamp, adjust the drip rate. & 51 & 72.9 & 69 & 98.6 & 0.63 \\
\hline $\begin{array}{l}\text { 26. Remain with the patient during the first } 5 \text { minutes to } 30 \\
\text { minutes and then obtain vital signs. }\end{array}$ & 45 & 64.3 & 46 & 65.7 & 0.77 \\
\hline 27. Obtain vital signs in 15 minutes. & 37 & 52.9 & 43 & 61.4 & 0.65 \\
\hline 28. Make sure that patient's call bell or light readily available. & 39 & 55.7 & 51 & 72.9 & 0.43 \\
\hline 29. Flush the administration set with normal saline solution. & 0 & 0.0 & 0 & 0.0 & --- \\
\hline 30. Second blood unit can be hung with same set. & 67 & 95.7 & 70 & 100.0 & 0.65 \\
\hline 31. After blood transfused clear IV tubing with normal saline. & 0 & 0.0 & 0 & 0.0 & -.- \\
\hline 32. $\quad$ Discard the empty blood container. & 70 & 100.0 & 70 & 100.0 & -.- \\
\hline \multicolumn{6}{|l|}{ If there is transfusion reaction } \\
\hline a. Stop the transfusion immediately if symptoms occur. & 70 & 100.0 & 70 & 100.0 & --- \\
\hline b. Disconnect the administration set from the IVcatheter. & 70 & 100.0 & 70 & 100.0 & --- \\
\hline $\begin{array}{l}\text { c. Obtain vital signs from the extremity opposite the } \\
\text { transfusion site. }\end{array}$ & 56 & 80.0 & 67 & 95.7 & 0.125 \\
\hline d. $\quad$ Maintain a patent IV catheter. & 55 & 78.6 & 67 & 95.7 & 0.681 \\
\hline e. Notify physician when blood has been stopped. & 67 & 95.7 & 70 & 100.0 & 0.584 \\
\hline $\begin{array}{l}\text { f. Place the administration set inside a biohazard } \\
\text { bag and send it to the blood bank immediately. }\end{array}$ & 0 & 0.0 & 49 & 70.0 & 0.001 \\
\hline Obtain urine specimens according to agency policy. & 2 & 2.9 & 25 & 35.7 & 0.001 \\
\hline h. Continue to monitor vital signs frequently. & 67 & 95.7 & 70 & 100.0 & 0.657 \\
\hline i. $\quad$ Administer medications as prescribed. & 70 & 100.0 & 70 & 100.0 & --- \\
\hline
\end{tabular}

Table (4): percentage of nurses with correct performance concerning Post-blood transfusion Procedure steps in audit and re-audit.

\begin{tabular}{|c|c|c|c|c|c|}
\hline \multirow{3}{*}{ Items } & \multicolumn{2}{|c|}{ audit } & \multicolumn{2}{|c|}{ Reaudit } & \multirow{3}{*}{ p-value } \\
\hline & & \multicolumn{2}{|c|}{$N=70$} & & \\
\hline & No & $\%$ & No & $\%$ & \\
\hline $\begin{array}{l}\text { 33. Discard the empty blood container and } \\
\text { administration set in the proper receptacle according to } \\
\text { agency policy. }\end{array}$ & 70 & 100 & 70 & 100 & --- \\
\hline $\begin{array}{l}34 . \quad \text { Documentation of the date, time(in/out) of } \\
\text { infusion, child's reaction, administration of medication } \\
\text { (pre/posttransfusion), patient's vital signs, and nursing } \\
\text { management. }\end{array}$ & 3 & 4.3 & 37 & 52.9 & 0.081 \\
\hline
\end{tabular}




\section{Years of experience}

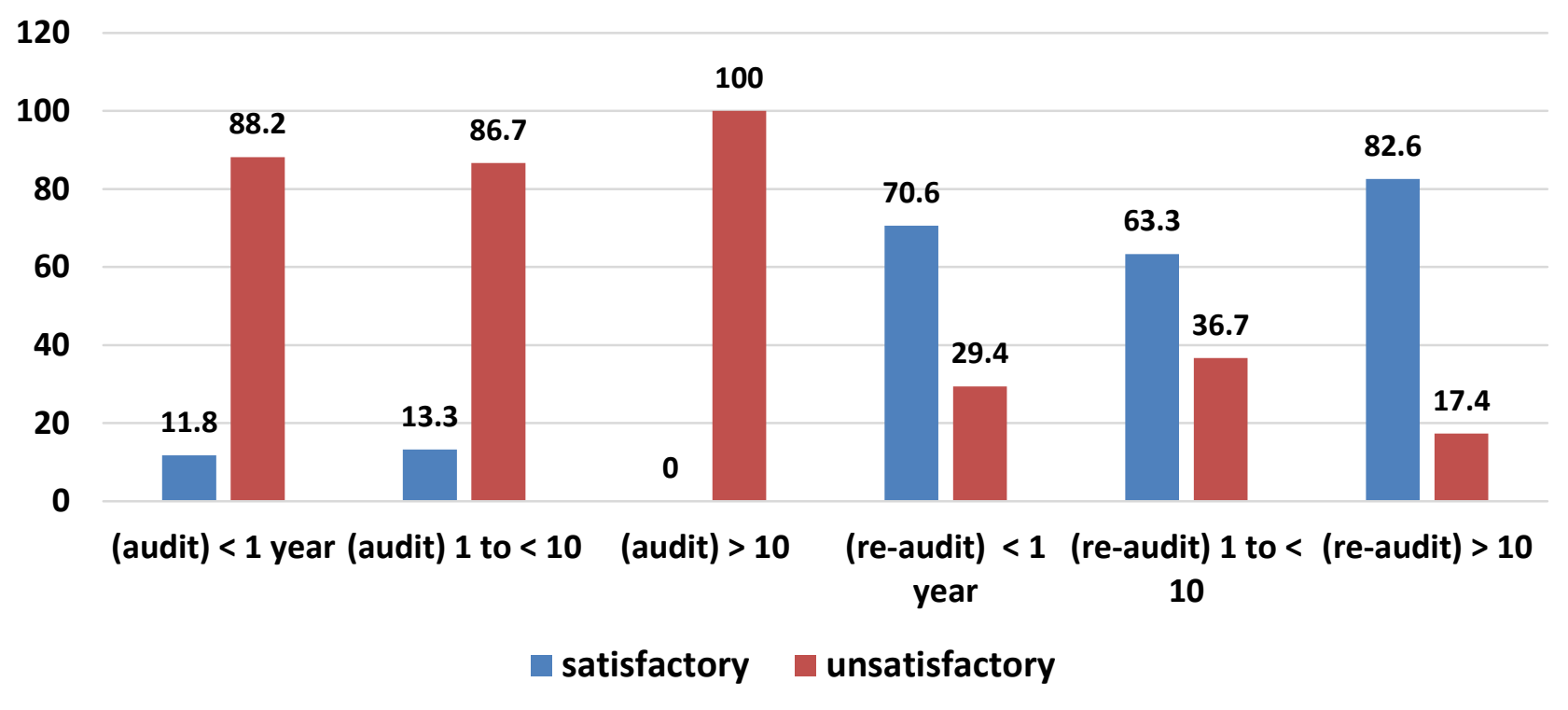

Figure (2): Relationship between Nurses performance level and their years of experience.

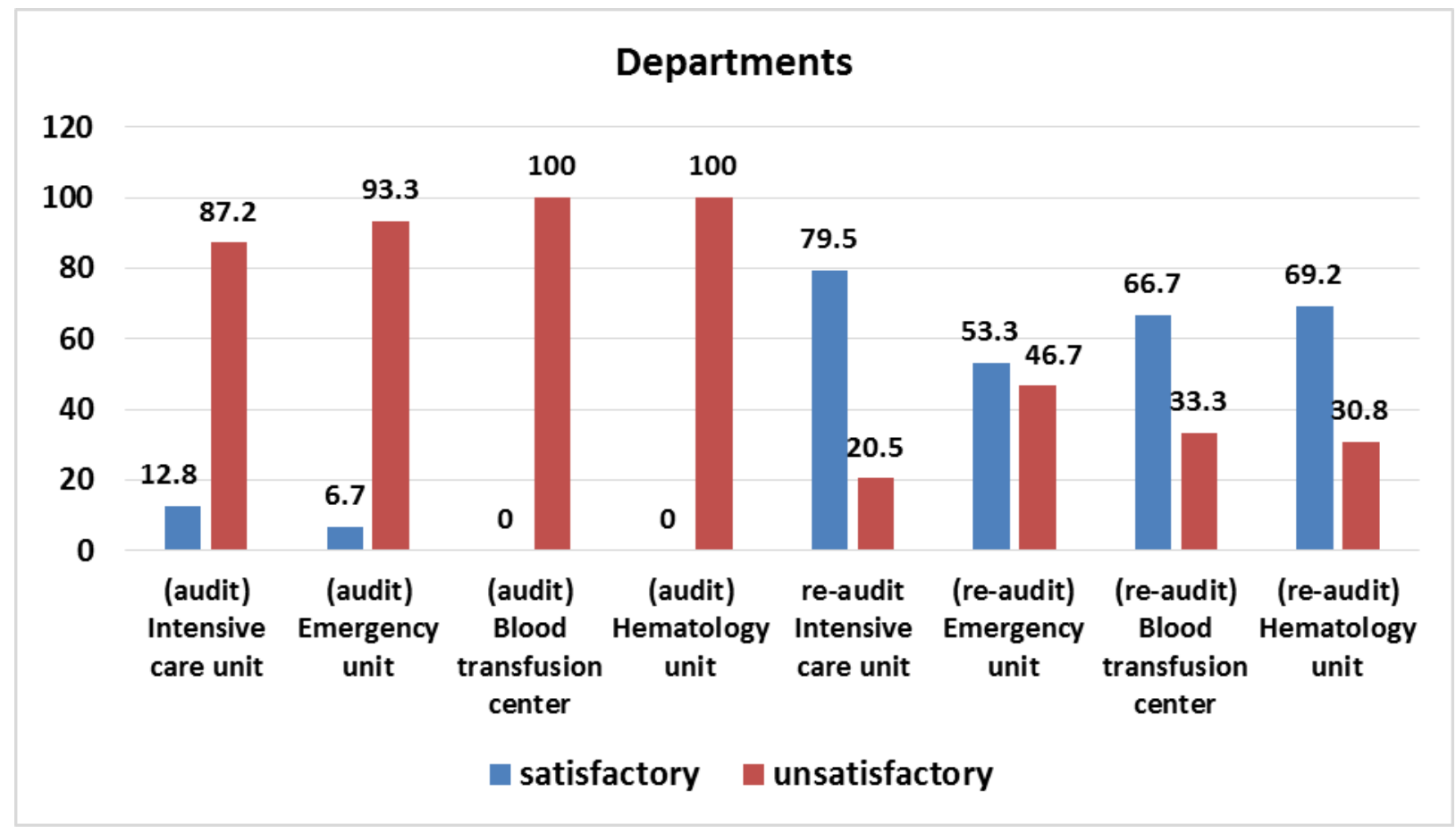

Figure (3): Relationship between Nurses practice level and their department. 


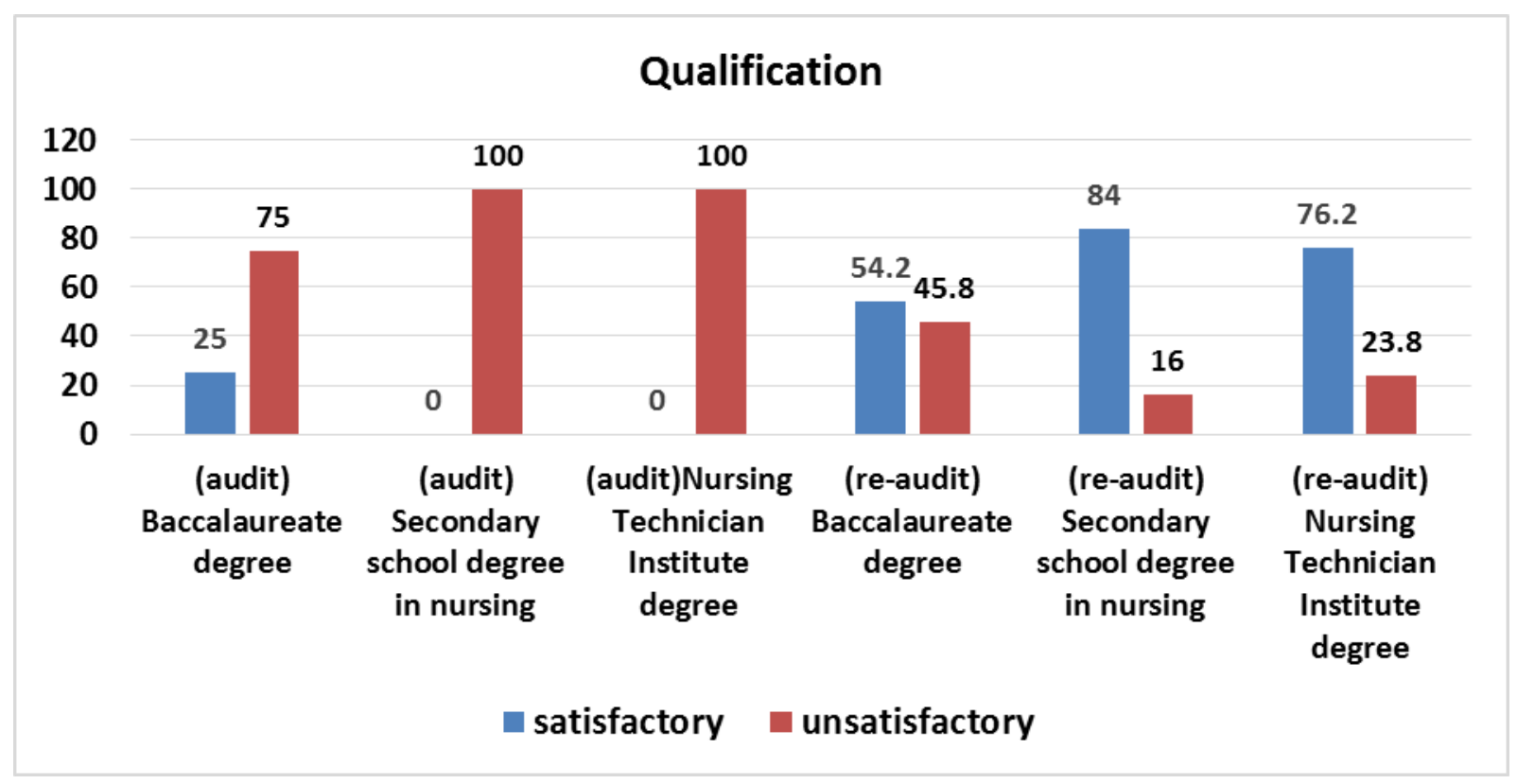

Figure (4): Relationship between Nurses practice level and their qualification.

Table (1): Shows the distribution of personal characteristics of studied nurses. It was found that; majority of nurses $(82.9 \%)$ aged from 20 to $<35$ years while $(17.1 \%)$ of them their ages were more than 30 years, Regarding the department, it was noticed that the percentage of nurses who were working in the studied units were $55.7 \%, 21.4 \%, 18.6 \%$ and $4.3 \%$ for Pediatric intensive care unit, Emergency unit, Blood transfusion center and Hematology unit, respectively. As for marital status; more than half of nurses $(62.9 \%)$ were married, while $(31.4 \%)$ of them were single and $(2.9 \%)$ of them were widowed, and $(2.9 \%)$ of them were divorced. It was found that more than half of nurses $(62.9 \%)$ were living in rural areas, while $(37.1 \%)$ of them were living in urban ones, it also shown from the table that; (35.7\%) of nurses had secondary school in nursing while $(34.3 \%)$ of them had baccalaureate degree in nursing, and $(30 \%)$ had Technical Institute of Nursing.

Figure (1): Shows the percentage distribution of nurses according to performance levels. It was found that majority of nurses $(91.4 \%)$ have unsatisfactory level of performance during blood transfusion while only $8.6 \%$ of them have satisfactory level. After reauditing, it was found that about three quarters of nurses (71.4\%) have satisfactory level of performance during blood transfusion while about one quarter $(28.6 \%)$ of they have unsatisfactory level.

Table (2): Percentage of nurses with correct performance concerning Pre-blood transfusion Procedure steps in audit and re-audit. It was found that seven points from Pre-Procedure steps were probably done with percent (>90\%) which are obtaining the blood product from the blood bank according to agency policy, administering any pretransfusion as prescribed, wearing gloves whenever handling blood products, rechecking the physician's order, closing the clamps on the administration set, inspecting the tubing for air. If air bubbles remain in the tubing, flicking the tubing with fingernail to mobilize the bubbles respectively. A set of steps which are totally neglected by the nurses were obtaining IV fluid containing normal saline $0.9 \%$, removing the protective covers from normal saline solution container port, hanging the normal saline solution container on IV pole and priming the administration set with normal saline respectively.

Table (3): Percentage of nurses with correct performance during blood transfusion Procedure steps in audit and reaudit. It was found that; ten points from during procedure steps were probably dome with percent $(>90 \%)$ hang the blood product container on the IV pole, compress the drip chamber, of the administration set and allow it to fill up half way, slowly open the roller clamp, if another unit of blood is required, the second blood unit can be hung with the same set, discard the empty blood containar and administration set in the proper receptacle according to agency policy, stop the transfusion immediately if symptons occur, disconnect the administration set from the IV catheter, notify physician as soon as the blood has been stopped and the patient has been assessed, continue to monitor 
vital signs frequently and administer medications as prescribed respectively. However, only three steps were not done by nurses:flush the administration set with normal saline, after blood transfused clear IV tubing with normal saline and place the administration set inside a biohazard bag and send it to the blood bank immediately, respectively.

Table (4): Percentage of nurses with correct performance concerning Post-blood transfusion Procedure steps in audit and re-audit. It was found that; all nurses (100\%) discard the empty blood container and administration set in the proper receptacle according to agency policy and after the re-auditing there are more than three quarter about $(52.9 \%)$ rather than only $(3 \%)$ of them document the date, time (in/out) of infusion, child's reaction, administration of medication (pre/post-transfusion), patient's vital signs, and nursing management.

Figure (2): Shows the relationship between total nurses' performance and their years of experience. The different was found between total nurse's performance concerning blood transfusion and their years of experience. Nurses who had $<1$ year of experience was 17 nurses with $(30.8 \%)$ satisfactory practice and $(5.6 \%)$ unsatisfactory practice while nurses who had 1 to $<10$ years of experience was 30 nurses with $(30.8 \%)$ satisfactory practice and $(77.8 \%)$ unsatisfactory practice. Nurses who had $>10$ years of experience was 23 nurses with $(38.5 \%)$ satisfactory practice and $(16.7 \%)$ unsatisfactory practice.

figure (3): Shows the relationship between total nurses' performance and their department. The different was found between total nurse's performance concerning blood transfusion and their department. Nurses who work at Intensive care unit was 39 nurses with $(69.2 \%)$ satisfactory performance and $(16.7 \%)$ unsatisfactory performance while nurses who work at Emergency unit was 15 nurses with (3.8\%) satisfactory performance and (16.7\%) unsatisfactory performance. nurses who work at Blood transfusion center was 3 nurses with (23.2\%) satisfactory performance and (5.6\%) unsatisfactory performance while nurses who work at Hematology unit was 13 nurses with (3.8\%) satisfactory performance and $(5.6 \%)$ unsatisfactory performance.

Figure (4): It shows the relationship between total nurses' performance and their qualification. The difference was found between total nurse's performance concerning blood transfusion and their qualification. Nurses who had Baccalaureate degree was 24 nurses with $(15.4 \%)$ satisfactory performance and $(88.9 \%)$ unsatisfactory performance while nurses who had Secondary school degree in nursing was 24 nurses with $(44.4 \%)$ satisfactory performance and $(11.1 \%)$ unsatisfactory performance while Nurses who had Nursing Technician Institute degree was 21 nurses with $(40.4 \%)$ satisfactory performance with no unsatisfactory performance.

\section{Discussion}

Transfuse blood and its component consider most common therapeutic to save patients' life, although transfusion improve patients' life, it is not without risks. Nurses had integral role of blood transfusion if they practice it properly, also nursing performance and safety of transfusion is reliant on nurses' knowledge and practice lead to diminish its risk. (Al Nasr, 2016).

The present study revealed that; generally, nurses' performance score was low due to child care who receiving blood transfusion. About one quarter of nurses $(24.3 \%)$ did not validate with another staff member the patient and blood product ID. Hogg et al., (2016) stated that the nurse ought to double-check the tags with the $\mathrm{ABO}$ group and Rh type and agrees with record also check that patient's blood has been cross-matched with another nurse.

During blood transfusion, nurse acting an essential role, also nurse must have acceptable performance to all steps of transfusion procedure to keep patient's safety. In the existing study all of studied sample were female and about one third were BSc in nursing. This result was in combatable with Silva et al., (2016) identified that more than two thirds of studied sample were female and have nursing bachelor's degree. The present study clarified that; most of participant did not obtain any training program; this result was in the same stroke with Ahmed (2011) who found as regarding to blood transfusion teaching program, majority of nurses did not join any.

Furthermore, recent study revealed that, Baccalaureate nurses had higher total score of performance than diploma nurses supported by Nurhusien et al., (2015) Morefore, Mohsen et al., (2016) reported that the level of performance of the nurses with baccalaureate degree is higher than the level of secondary school degree nurses. This outcome was not in the same line with Freahiywot et al., (2015) who reported that diploma nurses had two times more likely to performance when compared to those with Baccalaureate degree had knowledge and performance; due to the educational system of the nursing schools where in all three-year diploma nursing programs the percentage of practical courses is seventy to thirty percentage with thirty percentage theoretical supplement; however, in a four-year degree program the percentage of practical courses is below fifty percentage.

The current study found that all nurses included in the study reported that they had never received any training service in this field. This procedure requires 
skilled and trained professionals to achieve transfusion safety. This is supported with Valesca et al., (2016) who documented that blood transfusion requires trained and updated professionals which enable to maintain blood transfusion safety.

In relation to age, majority of nurses aged between 20-35-years old and they had higher mean in performance score These results agreed with Labrague et al., (2012) \& El-Sol \& Badawy (2016). About half of nurses $(44.2 \%)$ obtained vital sign including temperature before beginning the transfusion, this result was in contrast with Khalil, et al., (2013) who revealed that about one third of participant didn't recognize time for measuring vital signs post initiate blood transfusion.

About one fourth of nurses (37\%) obtain vital signs in fifteen minutes, then again in half hour and then hourly, Obsborn et al., (2010) stated that the nurse should monitor vital signs, compare vital signs against base line reading.

None of nurses obtain Iv fluid containing normal saline $0.9 \%$ and after blood has transfused use it to flush line in contrast with Hessig et al., (2014) who stated an IV administration set should be primed with $0.9 \%$ saline solution before transfusion, the IV cannula patency confirmed with a $0.9 \%$ saline flush and the blood administration set primed then with blood.

Another area of weakness in performance was the documentation. The majority of nurses had low score related to post procedural documentation. Rock et al., (2007) \& Hill, (2016) claimed that the lack of documentation of blood transfusions has been a problem in most hospitals for many years. Lynn et al., (2005) stated that documenting the procedure in patient's medical record, including patient assessment findings and any adverse reaction, document procedure in patient's medical record, document the time the infusion was started and completed, document the blood product volume and number, monitor patient for response to and effectiveness of the procedure and signature is very important.

The present study found that the majority of sample had good performance regarding how to deal with complications related to blood transfusion. This finding was in the same line with Yaghoobi et al. (2014) \& (Hussein \& Ebd-Elmaged (2015) who explained that most of studied sample had adequate performance related to complication, however this result in contrast with Shaymaa et al., (2013) and Silva et al., (2016) who observed that more than two thirds of studied sample had inadequate skills related to blood transfusion complication care.

The present study was in line with Gray (2007) who stated that the nurse should reverse the blood bag smoothly numerous times this step for mixing the cells with the plasma, bare the port on the blood bag by pulling back the tube, insert the remaining $\mathrm{Y}$ set spike into the blood bag, open the filter to expel any residual air within the filter, close the clamp, insert firmly the $\mathrm{Y}$ set into the IV catheter and run the transfusion gently (10 to $15 \mathrm{drop} / \mathrm{min}$ ) for first fifteen minutes.

Another zone of weakness in performance was checking that educated assent has been acquired. Formal signed assent by the parent is essential for blood transfusion Sabto (2011), and he issues encompassing transfusion must be examined with the parent and patient (where age-fitting) and substantial assent was taken and recorded preceding transfusion wherever conceivable. For neonatal exchange transfusion, the British Association of Perinatal Medicine prescribes formal composed assent. (Shaymaa et al., 2013)

\section{Conclusion}

The general conclusions that can be reached from this study are as follow:

It can be concluded that nurses working in blood transfusion center, Hematology unit, emergency unit and intensive care unit had low total score of performance as regards most of the aspects studied concerning in caring of children receiving blood transfusion.

The nurses with a baccalaureate degree had higher score of performance than other nurses with Secondary school degree in nursing and Nursing Technical Institute degree

After re-auditing a good improvement in performance were found, more than three quarter of nurses who had secondary school degree and Technical nursing institute graduates have satisfactory level of performance during blood transfusion.

The current study found that all nurses included in the study reported that they had never received any training service in this field. This procedure requires skilled and trained professionals to achieve transfusion safety.

\section{Recommendations}

1- Continuous in-service training for nurses through educational programs must be established by using tools for assessment of nurse's knowledge and performance frequently to improve the procedures implementation quality and practical monitoring.

2- Films and audiovisual conferences about care of children receiving blood transfusion should be done.

3- Particular attention should be given to the practical part in the training of nurses and nursing supervisors who work in the field of care of 
children receiving blood transfusion, this would help to improve nurse's skills

4- Educational courses given for nurses should be in Arabic, simple and small sessions and according to the level of understanding of each nurse because it is different from place to place.

5- Hospital should provide ongoing quality programs or workshops for nurses who are responsible of applying the blood transfusion procedure

6- Ongoing assessment and evaluation of nursing staff performance in infection control skills with blood transfusion procedure.

7- Availability of manual procedures for nurses to be aware of handling any problems that may arise.

\section{References}

1. Adams K., \& Tolich D., (2011): the patient's experience. Am J Nurs. 2011 Sep; 111(9):24-30; quiz 31-2.[PubMed] [Ref list]

2. Ahmed G., (2011): Effect of designed nursing protocol on nurse's knowledge and practice regarding Hemodialysis patients, submitted for partial fulfillment of master's Degree in medical and surgical Nursing Faculty of Nursing, Assiut University.

3. Al Nasr M., (2016): Assessment of Nurses' Performance Regarding Nursing Care of Patients Undergoing Blood Transfusion Published Thesis. Port Said-University. Faculty of Nursing Journal.

4. Baer, V., Henry, E., Lambert, D., Stoddard, R., Wiedmeier, S., Eggert, L., Ilstrup, S., \& Christensen, R., (2011). Implementing a program to improve compliance with neonatal intensive care unit transfusion guidelines was accompanied by a reduction in transfusion rate: a pre-post analysis within a multihospital health care system. Transfusion, 51, 264-269.

5. Bielby, L., Stevenson \& E., Wood, (2011): The Role Of The Transfusion Nurse In The Hospital And Blood Center. International Society Of Blood Transfusion, ISBT Science Series 2011; 6, 270-6.

6. British Committee for Standards in Haematology. (2014): Guideline for the use of anti-D immunoglobulin for the prevention of haemolytic disease of the fetus and newborn. Transfusion Medicine, 24, 8-20.

7. Davis T., (2012): Developing performance measures for patient blood management. Transfusion journal: V 51, P 2509-2500.

8. El-Sol A., \& Badawy A., (2016): "The Effect of a Designed Teaching Module Regarding Prevention of Central-Line Associated Blood Stream Infection on ICU Nurses' Knowledge and Practice," AJNS. http://www.sciencepublishinggroup.com/j/ajns ISSN: 2328-5745 (Print) ISSN: 2328-5753.
9. Freahiywot Teshager, Engeda, E., \& Workie Zemene Worku, W., (2015) "Knowledge, Practice, and Associated Factors towards Prevention of Surgical Site Infection among Nurses Working in Amhara Regional State Referral Hospitals, Northwest Ethiopia,". Surgery Research and Practice Vol. 2015 (2015), Article ID 736175,6 pages Available at: http://dx.doi.org/10.1155/2015/736175

10. Gray A., (2007): Safe Transfusion of Blood and Blood Componants, Nursing Standard, 21(51): pp.40-47.

11. Hazinski, M., (2013): children are different .nursing care of the critically ill child (pp.1-18).st louis, MO:Elsevier Mosby.

12. Hessig R., Arcand L., \& Frost M., (2014): The effects of an educational intervention on oncology nurses' attitude, perceived knowledge, and selfreported application of complementary therapies. Oncology Nursing Forum, 31 (1): pp. 71-78.

13. Hijji, B., Oweis, A., Dabbour, R., (2012): Measuring Knowledge Of Blood Transfusion: A Survey Of Jordanian Nurses. American International Journal Of Contemporary Research.2012;2(10).

14. Hijji B., Parahoo K., Hussein M., \& Barr O., (2013): Education and competence, Knowledge of blood transfusion among nurses, Journal of clinical nurses, vol 22, Issue 17-18, P.P. 25362550

15. Hill, Kelly A., "Standardized Blood Transfusion Documentation" (2016): Master's Projects and Capstones. 381 . https://repository.usfca.edu/capstone/381

16. Hogg G., Pirie E., \& Ker J., (2016): ABO group and $\mathrm{Rh}$ type agrees with the compatibility. Nurse Education and Practice, Volume 6, Issue 4, pp. 214-223.

17. Hussein A., \& Ebd-Elmaged E., (2015) : Effectiveness of Designed Nursing Guidelines on Reducing Anxiety Level among Patients Undergoing Magnetic Resonance Imaging. J Am Sci,11(11):8795]. (ISSN: 1545-1003). http://www.jofamericanscience.org. 9

18. Istaphanous G., Wheeler D., Lisco S., Shander A., (2011): Red blood cell transfusion in critically ill children: A narrative review. Pediatr Crit Care Med 2011;12(2):174-183 https://doi.org/10.1097/pcc.0b013e3181e30d09

19. Khalil, S., Mohammad, Z., El-Deen, M., \& Ahmed, N., (2013): Blood Transfusion. Impact Of Implementing A Designed Nursing Intervention Protocol On Nurses' Knowledge And Practice Regarding Patients Undergoing Blood Transfusion .Med. J. Cairo Univ.2013;81(2) 163- 
71.available

at:

Www.Medicaljournalofcairouniversity.Net

20. Knowles S., \& Cohen H., (2011): Serious Hazards of Transfusion (SHOT) Steering Group. The Annual SHOT Report. http://www.shotuk.org/wpcontent.

21. Labrague, L., Rosales R., \& Tizon, M., (2012): "Knowledge of and compliance with standards precautions among student nurses," International Journal of Nursing Practice. Aug,". 1(2):84-97. Available at http:// www.science pubco.com/index.php/IJANS Mahmud N. and Abdul

22. Lavoie J., (2011): Blood transfusion risks and alternative strategies in pediatric patients. Paediatr Anaesth; 21:14-24

23. Lehman E., \& Wilson M., (2009): Epidemic hepatitis $\mathrm{C}$ virus infection in Egypt: estimates of past incidence and future morbidity and mortality. J Viral Hepat 16: 650-658.

24. Marianne J., (2016): Facts1101, Drains peri. anesthesia nursing, A critical care approach, $6^{\text {th }}$ ed, ch 29, PP. 249 .

25. Mohamed, A., \& Shah, P., (2012): Transfusion associated necrotizing enterocolitis: a metaanalysis of observational data. Pediatrics, 129, 529-540.

26. Mohsen, M., Safaan, N., \& Okby, O., (2016): Nurses' Perceptions and Barriers for Adoption of Evidence Based Practice in Primary Care: Bridging the Gap. American Journal of Nursing Research, 4(2), 25-33.

27. Murphy M., Staves, J., \& Davies, A., (2009): How do we approach a major change program using the example of the development, evaluation, and implementation of an electronic transfusion management system? Transfusion, 49, 829-837.

28. Murphy M., Waters J., Wood E., (2013): Transfusing blood safely and appropriately. BMJ. 2013 Jul 16347:f4303. doi: 10.1136/bmj.f4303.

29. New H., (2006): Paediatric transfusion, Blackwell Publishing Ltd. Vox Sanguinis, Vox Sanguinis, 90, P.P.1-9

30. New, H., Berryman, J., Bolton-Maggs, P., Cantwell, C., Chalmers, E., Davies, T., \& Stanworth, S., (2016): Guidelines on transfusion for fetuses, neonates and older children. British journal of haematology, 175(5), 784-828.

31. Nuruhusien, N., Zewdu, F., Amsalu, S., \& Mehretie, Y., (2015): "Knowledge and practice of nurses towards prevention of pressure ulcer and associated factors in Gondar University Hospital, Northwest Ethiopia” (2015) doi: 10.1186/s12912-015-0076-8PMCID: PMC4450466. Available https://www.ncbi.nlm.nih.gov
32. Oldham J., Sinclair L., \& Hendry C., (2009): Right patient, right blood, right care: safe transfusion practice. British Journal of Nursing18, 312 .

33. Ramos S., Mohnle P., \& Weng Y., (2008): Investigators of the multicenter study of perioperative ischemia: MCSPI research group. The ongoing variability in blood transfusion practices in cardiac surgery. Transfusion: 12841299.

34. Rock, G., Berger, R., Filion, D., Touche, D., Neurath, D., Wells, G., \& Afzal, M., (2007): Documenting a transfusion: how well is it done? Transfusion, 47(4), 568-572 5p.

35. Sabto N., (2011): Patient Consent for Blood Transfusion. Advisory Committee on the Safety of Blood, Tissue and Organs. Available at: http://www.gov.uk/government/uploads/system(a ccessed 1 aug).

36. Scott, B., Frank C., \& Grimson, R., (2016): blood transfusion is associated with increased resource utilization, morbidity and mortality in cardiac surgery patient's, annuals of cardiac anaesthesia: IP:196.150.250.3.

37.Sellu D., Davis R., \& Vincent C., (2012): Assessment of blood transfusion competencies using objective structured clinical examination, Transfusion medicine, British blood transfusion society, vol 22, issue6.

38. Shaymaa S., Khalil, Zienab A., Mohammad, Manal E., El-Deen, \& Nagwa M., Ahmed, (2013): Impact of Implementing A Designed Nursing Intervention Protocol on Nurses' Knowledge and Practice Regarding Patients Undergoing Blood Transfusion, Med. J. Cairo Univ., Vol. 81, No. 2, June: 163-171, 2013 www.medicaljournalofcairouniversity.net)

39. Silva M., Torres G., Melo G., Costa I., Tiburcio M., \& Farias T., (2016): Conhecimento Acerca Do Processo Transfusional Da Equipe.De Enfermagem Da UTI De Um Hospital Universitário. Ciênc. Cuid.Saúde [Internet]. Out/Dez [Cited Fev 10]; 8(4): 571

40. Slonim, A., Joseph, J., Turenne, W., Sharangpani A., \& Luban, N., (2008): Blood transfusions in children: a multi-institutional analysis of practices and complications. Transfusion, 48, 73-80.

41.Smit E., Walther J., \& Lopriore E., (2008): Rhesus haemolytic disease of the newborn: Postnatal management, associated morbidity and long-term outcome. Semininars in Fetal and Neonatal Medicine, 13, 265-271.

42. Taylor C., (Ed.), Cohen H., Mold D., Jones H., (2010): on behalf of the Serious Hazards of 
Transfusion (SHOT) Steering Group. The Annual SHOT Report (2010).

43. Valesca R., Isabella B., Ana Carolina A., Maria M., \& Kelli B., (2016): "Transfusion monitoring: care practice analysis in a public teaching hospital," Einstein. 14(1):41-6. Einstein (São Paulo) vol.14 no.1 São Paulo Jan./Mar. Available at: http://www.scielo.br/scielo. php? script=sci...pid...45082016000100041

44. Wang J., Klein H., (2010): Red blood cell transfusion in the treatment and management of anemia: The search for the elusive transfusion trigger. Vox Sang. 2010; 98:2-11. [PubMed]

45. Wang R., Triulzi D., \& Qu L., (2012): Effects of prestorage vs poststorage leukoreduction on the rate of febrile nonhemolytic transfusion reactions to platelets. Am J Clin Pathol; 138:255-259

46. Widness John A., (2008): Pathophysiology of Anemia During the Neonatal Period, Including Anemia of Prematurity. Neoreviews. 2008;9(11):e520.

47. World Health Organization Universal access to safe blood transfusion, (2008): [updated; cited Feb]; Available from: http://extranet.who.int/iris/bitstream/123456789/3 31/1/WHO_EHT_08.03_eng.pdf. [Ref list]

48. World Health Organization Universal access to safe blood transfusion, (2010).

49. Yaghoobi, M., Shirzaie S., Yaghoobi P., Esmat Y., \& Nazanin B., (2014): Knowledge Level of The Staff s about Blood Transfusion in Hospitals in East of Iran/ Year::02(01). 91-96/Science Road Journal. 